\title{
Abnormally high HIP1 expression is associated with metastatic behaviors and poor prognosis in ESCC
}

\author{
YING SUN* ${ }^{*}$ YONGAN ZHOU* ${ }^{*}$ JINGHUA XIA, MIAOMIAO WEN, XUEJIAO WANG, \\ JIAO ZHANG, YANNING ZHANG, ZHIPEI ZHANG and TAO JIANG \\ Department of Thoracic Surgery, Second Affiliated Hospital of \\ Air Force Medical University, Xi'an, Shaanxi 710038, P.R. China
}

Received June 8, 2020; Accepted October 19, 2020

DOI: $10.3892 / 01.2020 .12340$

\begin{abstract}
Huntingtin interacting protein 1 (HIP1) is overexpressed in several human malignancies. However, the biological function of HIP1 in esophageal squamous cell carcinoma (ESCC), and its effect on the prognosis of patients remain unclear. The present study aimed to investigate HIP1 expression in ESCC via immunohistochemistry, reverse transcription-quantitative PCR and western blot analyses. The association between HIP1 expression and the clinicopathological characteristics of 173 patients with ESCC was statistically analyzed. The effect of HIP1 expression on patient prognosis was assessed via Kaplan-Meier and Cox regression analyses. Lentivirus-delivered RNA interfering technique was used to overexpress and downregulate HIP1 expression in ESCC cell lines. The results demonstrated that HIP1 expression was significantly higher in ESCC tissues compared with adjacent normal tissues, and HIP1 expression was associated with histological differentiation, tumor-node-metastasis stage and lymph node metastasis. Furthermore, the overall survival time of patients with high HIP1 expression was significantly shorter than those with low HIP1 expression. Cellular mobility demonstrated that overexpressing HIP1 increased ESCC proliferation, migration and invasion, whereas silencing HIP1 decreased ESCC proliferation, migration and invasion. Furthermore, overexpressing HIP1 induced ESCC cells to enter the S and G2 phases from the G1 phase, whereas HIP1 knockdown arrested the cell cycle in the G1 phase. Taken together, the results of the present study suggest that HIP1 is associated with proliferation and metastatic
\end{abstract}

Correspondence to: Professor Tao Jiang or Professor Zhipei Zhang, Department of Thoracic Surgery, Second Affiliated Hospital of Air Force Medical University, 569 Xinsi Road, Xi'an, Shaanxi 710038, P.R. China

E-mail: jiangtaotd@163.com

E-mail: zzpzyy@fmmu.edu.cn

*Contributed equally

Key words: huntingtin interacting protein 1, metastasis, prognosis, esophageal squamous cell carcinoma behaviors in ESCC, and thus may be used as a potential prognostic indicator for patients with ESCC.

\section{Introduction}

Molecular targeted therapy is considered a novel treatment method following surgery, radiotherapy and chemotherapy (1). Molecular targeted drugs, such as gefitinib (2), lapatinib (3), pazopanib (4), have been successfully applied for the treatment of lung, breast and colon cancers. However, there is currently a lack of effective targeted drugs for esophageal cancer. Thus, further studies are required to understand the tumorigenesis and identify therapeutic targets for esophageal cancer.

Huntingtin interacting protein 1 (HIP1) is a protein associated with Huntington's disease (5). HIP1, as an endocytic oncoprotein, participates in clathrin-mediated vesicle trafficking $(6,7)$. Previous studies have demonstrated the involvement of HIP1 in tumorigenesis $(8,9)$. For example, Marghalani et al (10) demonstrated that HIP1 contributes to the pathological diagnosis of Merkel cell carcinoma. Furthermore, Rao et al (11) reported that HIP1 is overexpressed in prostate and colon cancers, whereby its high expression levels promote cancer cell survival. Thus, it was hypothesized that HIP1 may be a novel oncogene in malignant tumor. However, the role of HIP1 in esophageal squamous cell carcinoma (ESCC) remains unclear. Thus, the present study aimed to investigate HIP1 expression in 173 ESCC tissues via immunohistochemical staining. In addition, the association between HIP1 expression and the clinicopathological characteristics of patients with ESCC was statistically analyzed. HIP1 was overexpressed and downregulated in ESCC cell lines, and its biological functions were investigated in vitro.

The results of the present study demonstrated that HIP1 expression was higher in ESCC tissues compared with adjacent normal tissues. Furthermore, high HIP1 expression was associated with promoting ESCC metastasis, while low HIP1 expression inhibited ESCC metastasis. Taken together, these results suggest that HIP1 may be a marker to predict the metastasis of patients with ESCC.

\section{Materials and methods}

Patients and tissue samples. A total of 178 paraffin-embedded ESCC tissues were randomly selected from the biological sample 
bank at the Department of Thoracic Surgery, Second Affiliated Hospital of Air Force Medical University (Xi'an, China), between December 2006 and February 2013. Patients who received preoperative chemotherapy, radiotherapy or other treatments were excluded from the present study. Among the 178 patients, 173 patients were confirmed ESCC (97.2\%), and five patients were confirmed esophagus adeno cancer (EAC; $2.8 \%$ ). Considering the small number of specimens, patients with EAC were also excluded from the present study. Among 173 patients, there were 139 men and 34 women (median age, 60 years; age range 41-79 years). Patient information, including age and sex were collected from the medical records. The last follow-up was on June 12, 2018, with a median follow-up period of 38 months (1-145 months). The present study was approved by the Regional Ethics Committee for Clinical Research of the Air Force Military Medical University (Xi'an, China; approval no. TDLL-201712-22). Written informed consent was provided by all patients prior to the study start for use of their medical records and tissue specimens for research purposes.

Cell culture. The ESCC cell lines (EC109, Kyse30, TE-10 and TE-11) were preserved at the Department of Thoracic Surgery, Second Affiliated Hospital of Air Force Medical University (Xi'an, China), while the human esophageal epithelial cell line (HEEpiC) was purchased from the American Type Culture Collection. All cells were maintained in RPMI-1640 medium (HyClone; GE Healthcare Life Sciences) supplemented with $10 \%$ fetal bovine serum (FBS, Gibco; Thermo Fisher Scientific, Inc, and $1 \%$ penicillin/streptomycin (cat. no. C0222, Beyotime Institute of Biotechnology), at $37^{\circ} \mathrm{C}$ in $5 \% \mathrm{CO}_{2}$.

Immunohistochemistry (IHC). Tumor tissue samples were fixed with $10 \%$ formaldehyde for $48 \mathrm{~h}$ at room temperature and embedded in paraffin. Paraffin-embedded tissue samples were cut into $4-\mu \mathrm{m}$-thick sections. Tissue sections were dewaxed using xylene, digested with urea for $30 \mathrm{~min}$ and incubated with $3 \%$ hydrogen peroxide for $30 \mathrm{~min}$ to inhibit endogenous peroxidase activity at room temperature. Subsequently, the tissue sections were repaired for $20 \mathrm{~min}(750 \mathrm{~W}$ for $5 \mathrm{~min}$ and $450 \mathrm{~W}$ for $15 \mathrm{~min}$ ) using a microwave and cooled in citric acid buffer (pH 6.0). Tissue sections were blocked with 5\% goat serum for $30 \mathrm{~min}$ and washed three times with PBS solution (5 min each time) at room temperature. The sections were incubated with HIP1 primary antibody (1:80; cat. no. 22231-1-AP; ProteinTech Group, Inc.) overnight at $4^{\circ} \mathrm{C}$. Following the primary incubation, tissue sections were incubated with contents of the EnVision ${ }^{\mathrm{TM}}$ Detection kit (cat. no. CW20355, Kangwei, http://cwbiotech.bioon.com. $\mathrm{cn} /$ ) at $37^{\circ} \mathrm{C}$ for $45 \mathrm{~min}$, according to the manufacturer's instructions (12). The sections were subsequently counterstained with hematoxylin for $90 \mathrm{secs}$ and treated with hydrochloric acid alcohol differentiation fluid for $7 \mathrm{sec}$ at room temperature.

Evaluation of IHC staining. Following IHC staining, tissue sections were observed in five randomly selected fields under a fluorescence microscope (Leica Microsystems $\mathrm{GmbH}$, DM4000B; magnification, x200). The total immunostaining score was calculated as the product of the proportion score and the intensity score (13). The proportion score represented the estimated fraction of positively stained tumor cells, as follows: $0,0-5 \% ; 1,6-25 \% ; 2,26-50 \% ; 3,51-75 \%$ and $4,76-100 \%$. The intensity score represented the estimated staining intensity, as follows: 0 , negative; 1 , weak; 2 , moderate and 3 , strong. These scores were measured according to the result of the degree multiplied by the score of the staining intensity, as follows: 0,$0 ; 1+, 1-4 ; 2+, 5-8$ and $3+, 9-12$. A score of 0 was considered negative, whereas scores $1+$ to $3+$ were considered positive. Thus, the total score ranged from 0-12.

Reverse transcription quantitative $(R T-q) P C R$. Total RNA was extracted from tissue samples and cell lines using TRIzol ${ }^{\circledR}$ reagent (Invitrogen; Thermo Fisher Scientific, Inc.), according to the manufacturer's protocol. Total RNA was reverse transcribed into cDNA using the Thermo scientific Revert Aid First Strand cDNA Synthesis kit (100rxns, Thermo Fisher Scientific, Inc.). qPCR was subsequently performed using the SYBR Green Premix Ex Taq II kit (cat. no. CW0957M; Kangwei, http://cwbiotech.bioon.com.cn/). Relative expression levels were calculated using the $2^{-\Delta \Delta C q}$ method (14) and normalized to the internal reference gene $\beta$-actin.

The following primer sequences were used for qPCR: HIP1 forward, 5'-GTTGTGGCCTCAACCATT-3' and reverse, 5'-ACCACTTCTTGCAGTGTAG-3'; and $\beta$-actin forward, 5'-CTCCATCCTGGCCTCGCTGT-3' and reverse, 5'-GCT GTCACCTTCACCGTTCC-3'. Relative expression levels were normalized to the internal reference gene $\beta$-actin.

Western blotting. Total protein was extracted from tissues and cells using RIPA lysate (cat. no. P0013; Beyotime Institute of Biotechnology). Total protein was quantified using the BCA Protein Assay kit (cat. no. 23227, Pierce; Thermo Fisher Scientific, Inc.). The extracted protein was mixed with the loading buffer (10x, cat. no. CW0027A; CWBio) and heated at $65^{\circ} \mathrm{C}$ for $30 \mathrm{~min}$. The proteins $(30 \mu \mathrm{g})$ were separated by SDS-PAGE $(5 \%$ concentrated glue and $12 \%$ separated glue). Subsequently, the proteins were transferred onto the polyvinylidene fluoride membranes (Beijing Solarbio Science \& Technology Co., Ltd.) via electroblotting (Bio-Rad Laboratories, Inc.). Membranes were blocked with 5\% skim milk powder, which was dissolved in TBST for $3 \mathrm{~h}$ at room temperature, and subsequently incubated with HIP1 primary antibody (cat. no. 22231-1-AP, monoclonal antibody, 1:1,000, ProteinTech Group, Inc.) and $\beta$-actin (cat. no. CW0097, polyclonal antibody, 1:2,500, CWBio) diluted with WB Antibody Diluent (P0023A; Beyotime Institute of Biotechnology) overnight at $4^{\circ} \mathrm{C}$. Following the primary incubation, the membranes were incubated with secondary antibody (1:5,000; cat. no. EK020; Zhuangzhi Bio, http://www.zhuangzhibio. com) diluted with WB Secondary Antibody Diluent (cat. no. P0023A; Beyotime Institute of Biotechnology) at room temperature for $35 \mathrm{~min}$. Membranes were washed six times with TBST, and protein bands were detected using the Millipore chromogenic kit (cat. no. WBKLS0500; Millipore). Relative quantitative analysis was performed using the GelDox XR system (Bio-Rad Laboratories, Inc.) (15).

Lentiviral construction of stable cell lines with overexpressed or downregulated HIPl and cell transfection. As demonstrated in Fig. 1E and F, HIP1 mRNA and protein expression levels are higher in EC109 cells compared with TE-10 cells, and lower in Kyser 0 cells compared with TE-11 cells. Thus, 
A

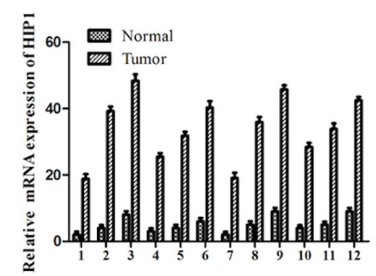

C

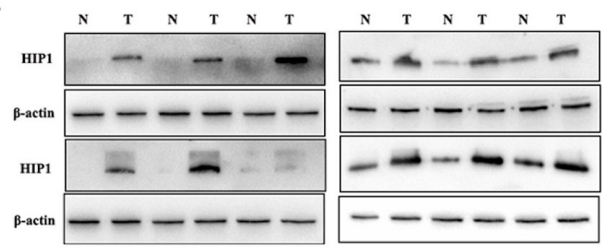

B

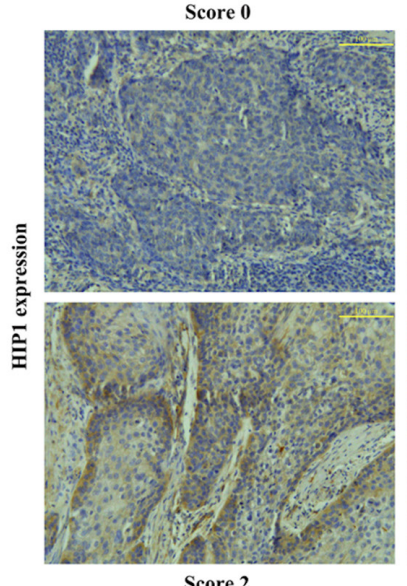

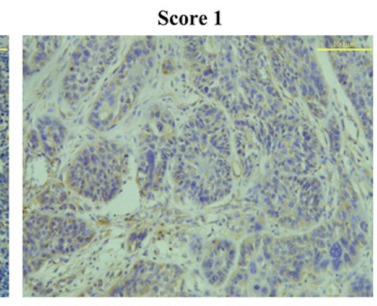

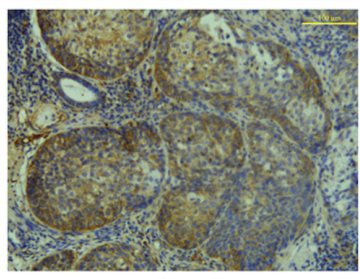

Score 3

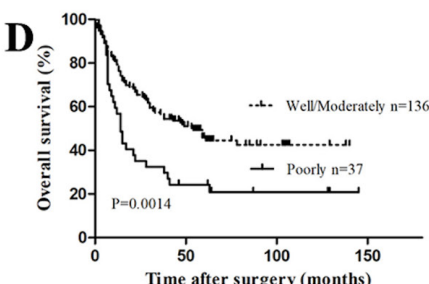

Time after surgery (months)

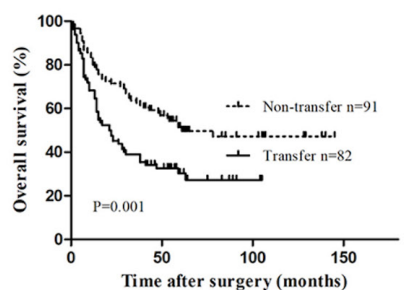

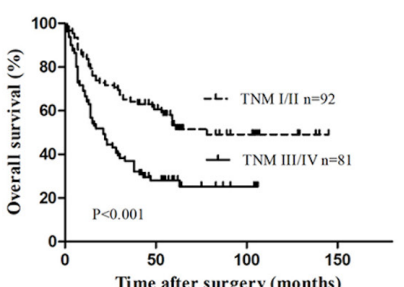

E

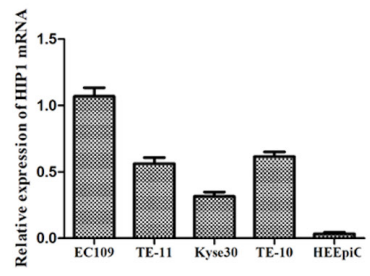

F

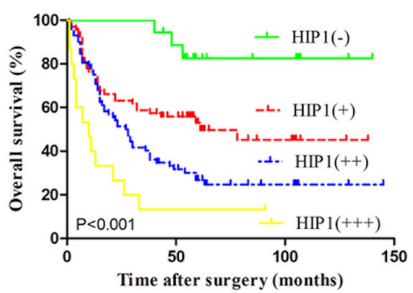

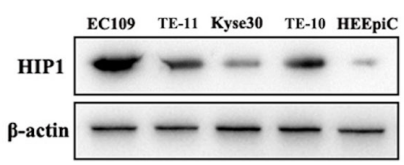

Figure 1. HIP1 is highly expressed in human ESCC and predicts a poor prognosis. (A) Reverse transcription-quantitative PCR analysis demonstrated that HIP1 mRNA expression levels were higher in ESCC tumor tissues compared with paracancerous tissues. (B) HIP1 expression in ESCC clinical specimens were divided into four groups (scores 0-3) by immunohistochemistry (magnification, x200). (C) Western blot analysis demonstrated that HIP1 protein expression levels were higher in ESCC tumor tissues compared with paracancerous tissues, and $\beta$-actin was used as the internal control. (D) Malignant differentiation (poor), late TNM stages (III-IV), transferred lymph node and high HIP1 expression were significantly associated with poor overall survival in patients with ESCC. (E) HIP1 mRNA expression levels were higher in ESCC cells compared with normal HEEpiC cells. (F) HIP1 protein expression levels were higher in ESCC cells compared with normal HEEpiC cells, and $\beta$-actin was used as the internal control. Data are presented as the mean \pm standard deviation. HIP1, huntingtin interacting protein 1 ; ESCC, esophageal squamous cell carcinoma; T, tumor; N, normal; TNM, tumor-node-metastasis; HEEpiC, human esophageal epithelial cell line.

EC109 was selected as the cell line where lentivirus interfered with the expression of the HIP1 gene, and Kyse 30 was selected as the cell line that promoted the expression of the HIP1 gene.

To stably overexpress (OE) the HIP1 gene, Kyse30 cells were infected with a lentivirus vector encoding the full-length sequence of human HIP1 gene. The untargeted sequence was used as OE-control group. Untreated cells were used as the control group. When the infection efficiency of cells treated with lentivirus green fluorescent protein (GFP) reached $80 \%$, and the results of RT-qPCR and western blotting found that significantly improving expressions of HIP1 mRNA and protein, the overexpression was considered successful.

EC109 cells were infected with hU6-MCSCMV-EGFP-lentivirus or an empty lentiviral control vector (Shanghai GeneChem Co., Ltd.) to inhibit HIP1 gene expression (Genebank no. 3092). The short hairpin (sh)RNA HIP1 sequences were as follows: \#1, 5'-AAGCTATTCAGGTGC TCAT-3'; \#2, 5'-TTCAATTTCAACAGTCAAA-3'; and \#3, 5'-TCTTCCAAACAGTATTCAA-3', and the shRNA control sequence was as follows: 5'-TTCTCCGAACGTGTCACGT-3'.
The untargeted sequence was used as the shRNA-control group, and untreated cells were used as the control group. When the infection efficiency of cells treated with lentivirus green fluorescent protein (GFP) reached $80 \%$, and the results of RT-qPCR and western blot analyses demonstrated significant inhibition of HIP1 mRNA and protein levels, then the lentivirus interference succeeded.

MTT assay. After 6 days of lentivirus vector overexpression or shRNA infection, the treated cells were seeded into 96 -well plates at a density of $4 \times 10^{3}$ cells/well. Cell viability was measured at days 1, 2, 3, 4, 5 and 6 following incubation at $37^{\circ} \mathrm{C}$ in $5 \% \mathrm{CO}_{2}$. A total of $20 \mu \mathrm{l} \mathrm{MTT}$ reagent $(5 \mathrm{mg} / \mathrm{ml}$, dissolved in PBS; Sigma-Aldrich; Merck KGaA) was added into each well and incubated at $37^{\circ} \mathrm{C}$ for $4 \mathrm{~h}$. Following the MTT incubation, the purple formazan crystals were dissolved using $150 \mu \mathrm{l}$ dimethyl sulfoxide and cell viability was subsequently analyzed at a wavelength of $570 \mathrm{~nm}$ using an ELISA detector (Thermo Fisher Scientific, Inc.), and the growth curve was plotted according to the OD value (15). 
Cell cycle analysis. The effect of HIP1 expression on ESCC cell cycle distribution was assessed via flow cytometry. Flow cytometric analysis was performed as previously described (15).

Wound healing assay. The wound healing assay was performed as previously described (16). Briefly, both transfected and untreated Kyse30 and EC109 cells were harvested and seeded into 6 -well plates at a density of $5 \times 10^{5}$ cells/well, 5 days post-lentiviral vector overexpression or shRNA infection. Cells were incubated overnight at $37^{\circ} \mathrm{C}$ in $5 \% \mathrm{CO}_{2}$ until they reached $80 \%$ confluence, and the monolayer was subsequently scratched using a $200 \mu 1$ pipette tip. The debris was removed and fresh serum-free RPMI-1640 medium (HyClone; GE Healthcare Life Sciences) was added to the wells. Cells were captured at 0,24 and $48 \mathrm{~h}$ using a fluorescence microscope (Zeisis, AXIOVERT 40C; magnification, x200). Cell migration was analyzed using ImageJ software (version 1.48u; National Institutes of Health) at three different sites from each wound area of scratch, at each time point. The percentage change in migration was determined by comparison of the differences in wound width.

Migration and invasion assays. The migration and invasion assays were performed in vitro as previously described (8) using $8 \mu \mathrm{m}$ pore size Transwell chambers (Corning, Inc.), according to the manufacturer's protocol. For the invasion assay, Matrigel ( $5 \mathrm{mg} / \mathrm{ml}$; Corning, Inc.) was diluted in $1 \mathrm{mg} / \mathrm{ml}$ ice-cold RPMI-1640 medium supplemented with 10\% FBS. An aliquot of $200 \mu \mathrm{l}$ diluted Matrigel was added to the upper Transwell chambers and incubated for $4 \mathrm{~h}$ at $37^{\circ} \mathrm{C}$. A total of $1 \times 10^{5}$ transfected and untreated Kyse30 and EC109 cells were plated in the upper chambers in $400 \mu \mathrm{l}$ RPMI-1640 medium (HyClone; GE Healthcare Life Sciences) without FBS. RPMI-1640 medium $(600 \mu \mathrm{l})$ supplemented with 10\% FBS was plated in the lower chambers as a chemo attractant. Following incubation for $48 \mathrm{~h}$ at $37^{\circ} \mathrm{C}$, the non-invasive cells in the upper chambers were carefully removed using a cotton swab, while the invasive cells in the lower chambers were fixed in dehydrated alcohol for $30 \mathrm{~min}$ at room temperature and subsequently stained with $4 \mathrm{mg} / \mathrm{ml}$ crystal violet for $10 \mathrm{~min}$ at room temperature. Stained cells well counted in five randomly selected fields using a fluorescence microscope (magnification, x200).

Statistical analysis. Statistical analysis was performed using SPSS 18.0 software (SPSS, Inc.). Data are presented as the mean \pm standard deviation. All experiments were performed in triplicate. As the data were not normally distributed, non-parametric tests were used in the present study. The difference in HIP1 expression among three or more groups was assessed using the Kruskal-Wallis $\mathrm{H}$ and Mann-Whitney U tests. Survival analysis was performed using the Kaplan-Meier method, and the Cox proportional hazards model was used for multivariate analysis. $\mathrm{P}<0.05$ was considered to indicate a statistically significant difference.

\section{Results}

Patient characteristics. The clinicopathological data of 173 patients with ESCC are presented in Table I. Among these patients, 139 were men and 34 were women, with a
Table I. Patient characteristics $(n=173)$.

\begin{tabular}{lcc}
\hline Characteristic & Number of cases, $\mathrm{n}$ & $\%$ \\
\hline Age, years & & \\
Median & 60 & \\
Range & $41-79$ & \\
Sex & & 80.3 \\
Male & 139 & 19.7 \\
Female & 34 & \\
Smoking history & & 53.2 \\
Smoker & 92 & 46.8 \\
Non-smoker & 81 & \\
Pathological type & & \\
Squamous cell carcinoma & 168 & 2.9 \\
Adenocarcinoma & 5 & 21.4 \\
Differentiation & & 57.2 \\
Well & 37 & 21.4 \\
Moderate & 99 & \\
Poor & 37 & 53.2 \\
TNM stage & & 46.8 \\
I-II & 92 & \\
III-IV & 81 & 52.6 \\
Primary tumor size, cm & & 47.4 \\
$\leq 4$ & 91 & \\
$>4$ & 82 & \\
Lymph node metastasis & 82 & \\
Yes & 91 & \\
No & & \\
\hline
\end{tabular}

TNM, tumor-node-metastasis.

median age of 60 years (age range, $41-79$ years). Among the 173 patients, 37 cases were highly differentiated (21.4\%), 99 cases were moderately differentiated $(57.2 \%)$ and 37 cases were poorly differentiated $(21.4 \%)$. With regards to the tumor-node-metastasis (TNM) stage, 92 cases were classified as stages I-II (53.2\%), while 81 cases were classified as stages III-IV (46.8\%). All tumors were staged according to the pathological tumor/node/metastasis (p-TNM) classification (8th edition) of the International Union against Cancer (17).

HIP1 is highly expressed in human ESCC tissues and cell lines, and predicts a poor prognosis. HIP1 mRNA expression was significantly higher in ESCC tissues compared with adjacent normal tissues (Fig. 1A). IHC analysis demonstrated that there were 155 positive results of HIP1 in ESCC tissues $(89.6 \%, 155 / 173)$, which was higher than that of HIP1 in adjacent normal tissues $(23.1 \%, 40 / 173)$. The ESCC staining results were sub-divided into four groups: HIP1 negative group (score 0), low HIP1 expression group (score 1), moderate HIP1 expression group (score 2) and high HIP1 expression group (score 3). The HIP1 positive rate in the ESCC tissues of the moderate and high groups $(50.3 \%)$ was higher than that in the low group (39.3\%) (Fig. 1B). Furthermore, HIP1 protein 
Table II. Association between HIP1 expression and the clinicopathological characteristics of patients with esophageal squamous cell carcinoma.

\begin{tabular}{|c|c|c|c|c|c|c|}
\hline \multirow[b]{2}{*}{ Characteristic } & \multirow[b]{2}{*}{ Number of patients, $n$} & \multicolumn{4}{|c|}{ HIP1 expression } & \multirow[b]{2}{*}{ P-value } \\
\hline & & - & + & ++ & +++ & \\
\hline Sex & & & & & & 0.281 \\
\hline Male & 139 & 17 & 48 & 60 & 14 & \\
\hline Female & 34 & 1 & 20 & 12 & 1 & \\
\hline Age, years & & & & & & 0.427 \\
\hline$\leq 60$ & 78 & 5 & 33 & 32 & 8 & \\
\hline$>60$ & 95 & 13 & 35 & 40 & 7 & \\
\hline Smoking history & & & & & & 0.911 \\
\hline Smoker & 92 & 14 & 32 & 34 & 12 & \\
\hline Non-smoker & 81 & 4 & 36 & 38 & 3 & \\
\hline Primary tumor size, $\mathrm{cm}$ & & & & & & 0.140 \\
\hline$\leq 4$ & 91 & 8 & 33 & 40 & 10 & \\
\hline$>4$ & 82 & 10 & 35 & 32 & 5 & \\
\hline Differentiation & & & & & & $<0.001$ \\
\hline Well & 37 & 7 & 22 & 8 & 0 & \\
\hline Moderate & 99 & 6 & 34 & 48 & 11 & \\
\hline Poor & 37 & 5 & 12 & 16 & 4 & \\
\hline TNM stage & & & & & & $<0.001$ \\
\hline I-II & 92 & 12 & 46 & 30 & 4 & \\
\hline III-IV & 81 & 6 & 22 & 42 & 11 & \\
\hline Lymph node metastasis & & & & & & $<0.001$ \\
\hline Yes & 82 & 4 & 26 & 40 & 12 & \\
\hline No & 91 & 14 & 42 & 32 & 3 & \\
\hline
\end{tabular}

HIP1, huntingtin interacting protein 1; TNM, tumor-node-metastasis.

expression was significantly higher in ESCC tissues compared with the adjacent normal tissues (Fig. 1C).

The results demonstrated that high positive HIP1 expression was significantly associated with moderate and poor differentiation, TNM stages III-IV and lymph node metastasis, while low positive HIP1 expression was significantly associated with well differentiation $(\mathrm{P}<0.001)$, TNM stages I-II $(\mathrm{P}<0.001)$ and lymph node non-metastasis $(\mathrm{P}<0.001)$ (Table II). Kaplan-Meier survival analysis demonstrated that differentiation $(\mathrm{P}=0.001)$, TNM stages $(\mathrm{P}<0.001)$, lymph node metastasis $(\mathrm{P}=0.001)$ and HIP1 expression $(\mathrm{P}<0.001)$ were all significantly associated with the overall survival (OS) time of patients with ESCC (Fig. 1D and Table III). Cox regression analysis indicated that differentiation $(\mathrm{P}=0.037)$, TNM stages $(\mathrm{P}=0.014)$ and HIP1 expression $(\mathrm{P}=0.001)$ were significant prognostic influences for OS (Table IV).

Higher HIP1 mRNA levels were detected in ESCC cell lines compared with HEEpiC cells. With regards to the ESCC cell lines, HIP1 mRNA expression was higher in EC109 and TE-10 cells and lower in Kyse30 and TE-11 cells (Fig. 1E). HIP1 protein expression levels were significantly higher in ESCC cells compared with HEEpiC cells. With regards to the ESCC cell lines, HIP1 protein expression was higher in EC109 and T10 cells, and lower in Kyse30 and T11 cells (Fig. 1F).
Silencing HIPl expression by lentivirus-delivered RNA interfering. To further investigate the underlying molecular mechanism of HIP1 in ESCC, EC109 cells were infected with shRNA-HIP1 (\#1, \#2 and \#3) and shRNA-control. The infection efficiency of green fluorescent protein (GFP) in EC109 cells infected with shRNA-HIP1-3 was 80 85\% after 3 days of infection, at a multiplicity of infection (MOI) of 10 (Fig. 2A). After 3 days of interfering, RT-qPCR and western blot analyses were performed to determine the knockdown efficiency, respectively. The results demonstrated that HIP1 mRNA and protein expressions levels were significantly inhibited in cells transfected with shRNA-HIP1-3 ( $\mathrm{P}<0.05$; Fig. 2B and C), and moderately decreased by the other two shRNAs (shRNA-HIP1-1 and shRNA-HIP1-2 compared with the shRNA-control group and control group. Thus, shRNA-HIP1-3 was selected for further lentivirus-delivered RNA interfering experiments. The successful establishment of a HIP1 gene silencing lentivirus provided a useful tool for further investigating the function of HIP1 in ESCC cell lines.

HIPI knockdown significantly suppresses ESCC cell proliferation, migration and invasion. The results of the MTT assay demonstrated that shRNA-HIP1 cells proliferated at a slower rate compared with the shRNA-control and control group cells, whereby the difference was statistically significant from day 4 (Fig. 3A). The results of the 
Table III. Kaplan-Meier survival analysis of variables affecting survival in patients with esophageal squamous cell carcinoma.

\begin{tabular}{|c|c|c|c|c|}
\hline Variable & Number of patients, $\mathrm{n}$ & Mean overall survival, months & $95 \%$ CI, months & P-value \\
\hline Total, $\mathrm{n}$ & 173 & 68.600 & $59.052-78.148$ & \\
\hline \multicolumn{5}{|l|}{ Age, years } \\
\hline$\leq 60$ & 78 & 65.663 & $52.122-79.205$ & 0.685 \\
\hline$>60$ & 95 & 69.873 & $56.979-82.767$ & \\
\hline \multicolumn{5}{|l|}{ Sex } \\
\hline Male & 139 & 63.366 & $53.302-73.429$ & 0.175 \\
\hline Female & 34 & 83.054 & $60.842-105.265$ & \\
\hline \multicolumn{5}{|l|}{ Smoking history } \\
\hline Never & 81 & 69.335 & $55.276-83.395$ & 0.794 \\
\hline Ever & 92 & 65.363 & $53.097-77.630$ & \\
\hline \multicolumn{5}{|l|}{ Differentiation } \\
\hline Well + moderate & 136 & 73.469 & $63.027-83.910$ & 0.001 \\
\hline Poor & 37 & 42.961 & $25.411-60.512$ & \\
\hline \multicolumn{5}{|l|}{ TNM stage } \\
\hline I-II & 92 & 85.222 & $72.178-98.267$ & $<0.001$ \\
\hline III-IV & 81 & 39.948 & $30.924-48.973$ & \\
\hline \multicolumn{5}{|c|}{ Lymph node metastasis } \\
\hline No & 91 & 82.656 & 69.632-95.679 & 0.001 \\
\hline Yes & 82 & 41.865 & $32.663-51.067$ & \\
\hline \multicolumn{5}{|l|}{ HIP1 expression } \\
\hline--+ & 86 & 86.883 & $73.578-100.187$ & $<0.001$ \\
\hline++-+++ & 87 & 48.335 & $36.683-59.987$ & \\
\hline
\end{tabular}

CI, confidence interval; TNM, tumor-node-metastasis; HIP1, huntingtin interacting protein 1.
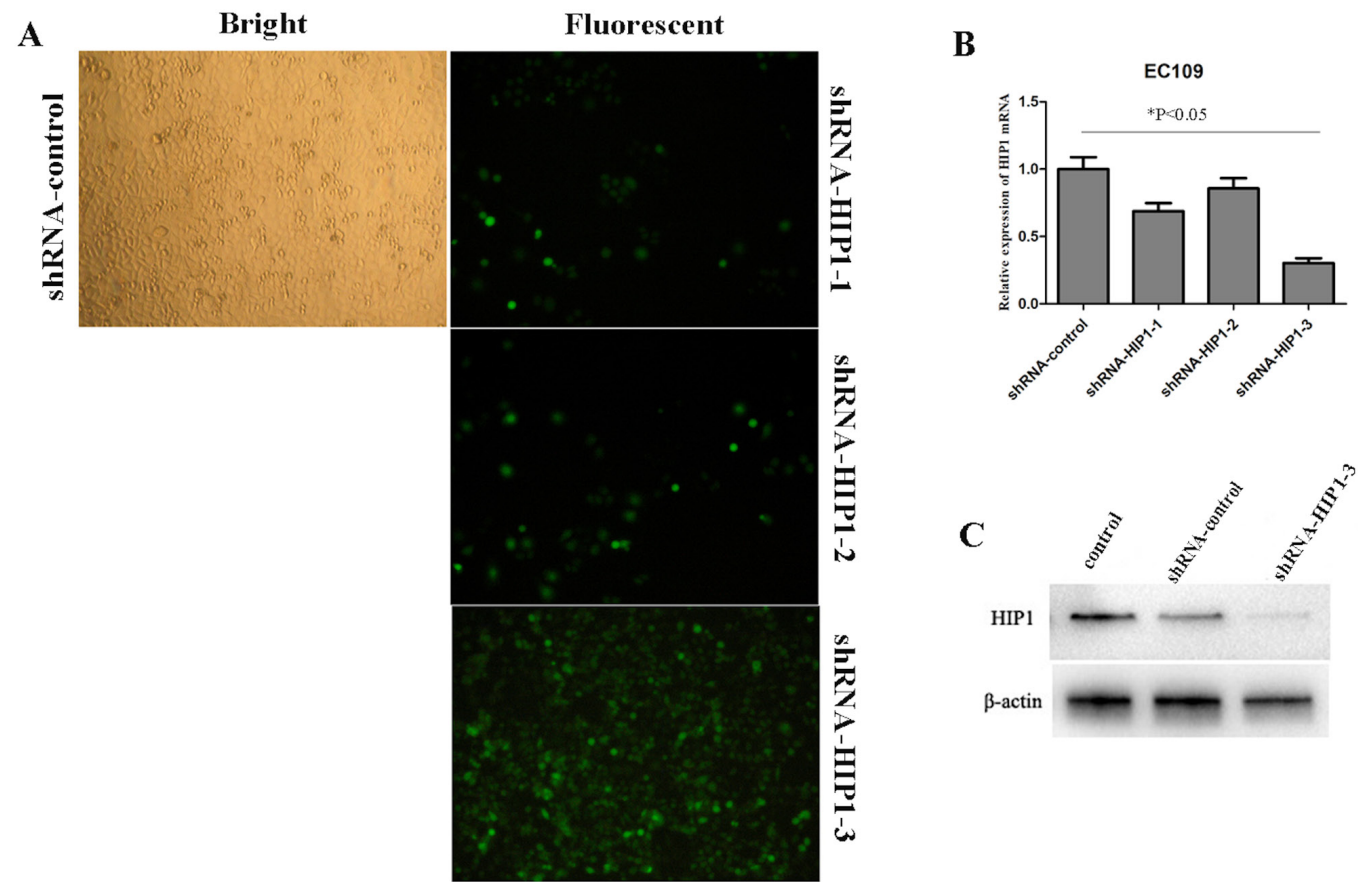

Figure 2. HIP1 expression is significantly inhibited in EC109 cells transfected with shRNA-HIP1. (A) Micrograph of EC109 cells infected with shRNA-HIP1 for 3 days in bright and fluorescent fields (magnification, 100x). The results demonstrated that $>80 \%$ of cells expressed green fluorescent protein in shRNA-HIP1-3. (B) Reverse transcription-quantitative PCR analysis demonstrated that HIP1 mRNA expression was inhibited in cells transfected with shRNA-HIP1-1 and shRNA-HIP1-2 compared with the shRNA-control and control groups, while HIP1 mRNA expression was significantly inhibited in cells transfected with shRNA-HIP1-3. (C) Western blot analysis demonstrated that HIP1 protein expression in cells transfected with shRNA-HIP1-3 was remarkably lower compared with the of shRNA-control and control cells. ${ }^{*} \mathrm{P}<0.05$. HIP1, huntingtin interacting protein 1 ; sh, short hairpin. 
Table IV. Multivariate analysis for overall survival according to Cox proportional hazards model.

Multivariate analysis

Variable

Category

HR (95\% CI)

P-Value

Differentiation

TNM stage

Poor/well + moderate

1.603 (1.030-2.496)

0.037

I-II/III-IV

$0.593(0.390-0.901)$

0.014

HIP1 expression

--+/++-+++

2.004 (1.310-3.067)

0.001

TNM, tumor-node-metastasis; HIPI, HIP1, huntingtin interacting protein 1; HR, hazard ratio; CI, confidence interval.

A

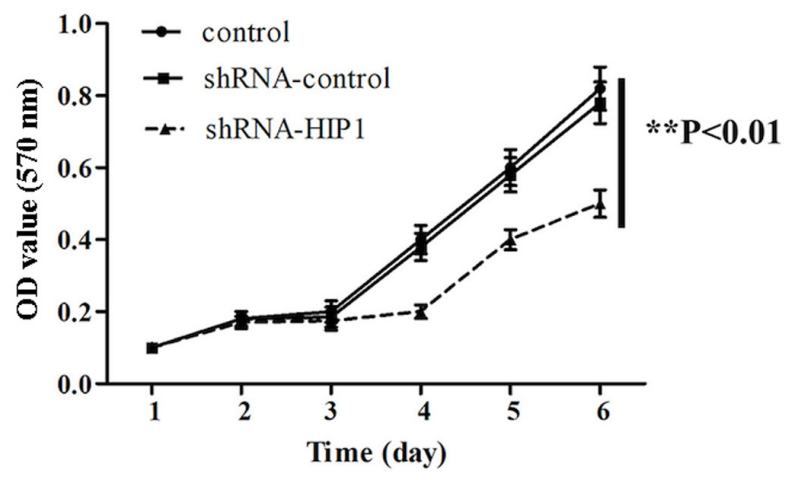

B
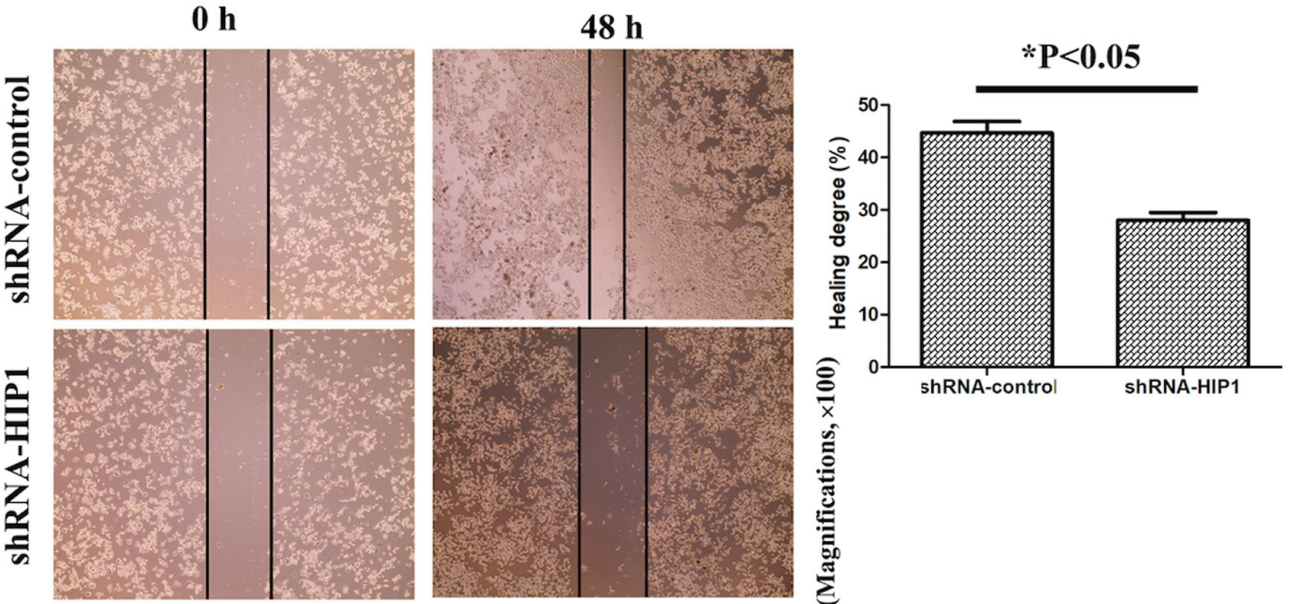

C

shRNA-control

ShRNA-HIP1
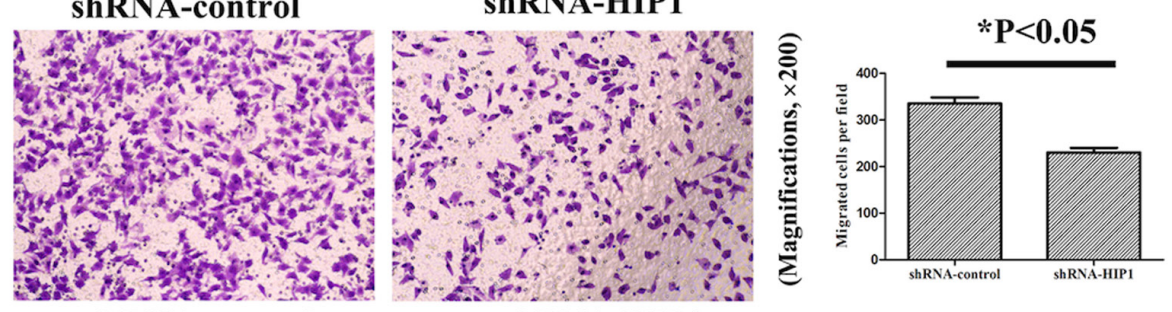

D

shRNA-control

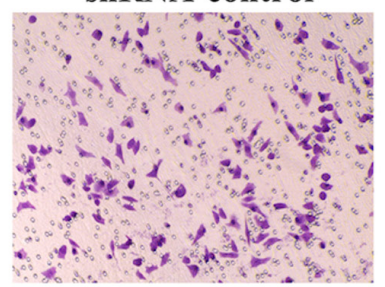

shRNA-HIP1

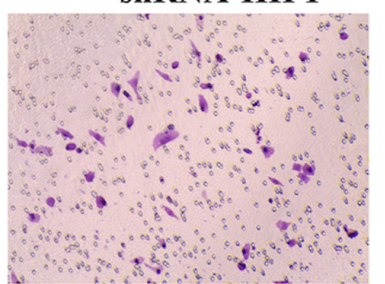

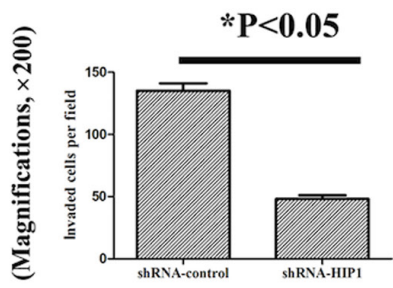

Figure 3. HIP1 knockdown significantly suppresses esophageal squamous cell carcinoma cell proliferation, migration and invasion. (A) The results of the MTT assay demonstrated that shRNA-HIP1 cells proliferated at a slower rate, in a time-dependent manner, compared with the shRNA-control and control cells. (B) The wound healing and (C) Transwell migration assays demonstrated that HIP1 knockdown inhibited the migratory ability of EC109 cells (magnifications, x100 and x200, respectively). (D) The Transwell invasive assay demonstrated that HIP1 knockdown inhibited the invasive ability of EC109 cells (magnification, $\mathrm{x} 200)$. ${ }^{\mathrm{P}} \mathrm{P}<0.05,{ }^{* *} \mathrm{P}<0.01$. HIP1, huntingtin interacting protein 1 ; sh, short hairpin; OD, optical density. 
A
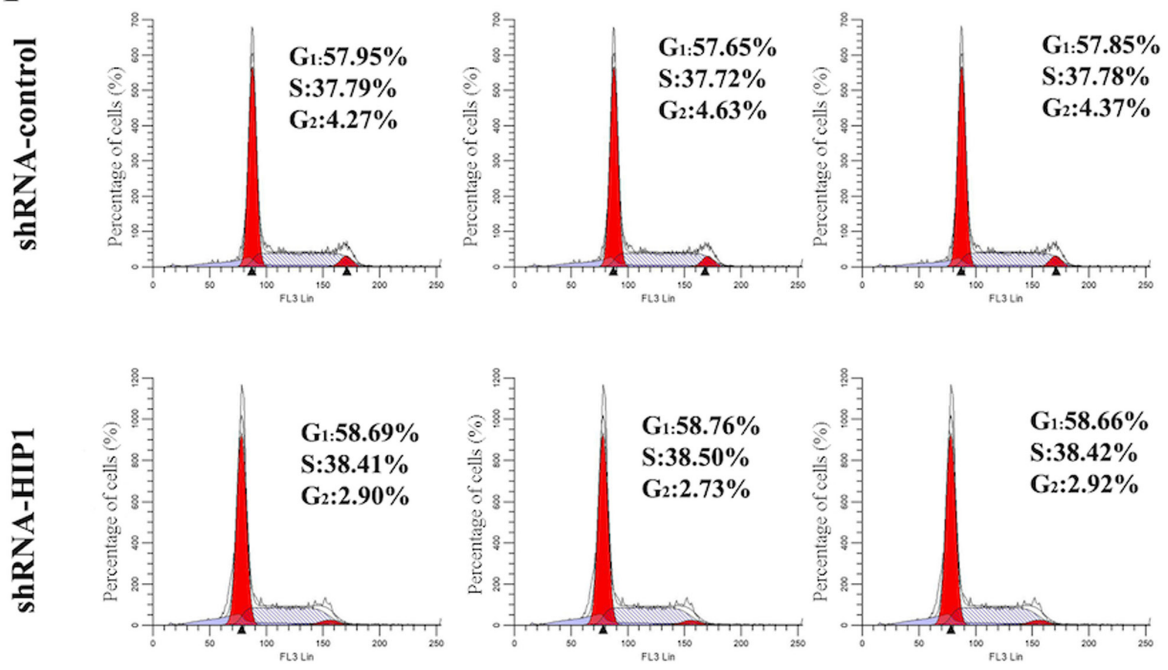

B

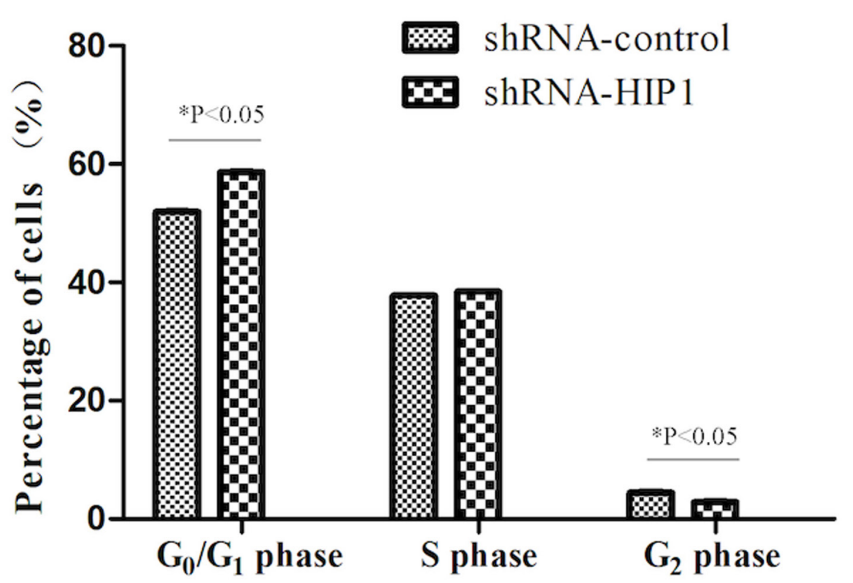

Figure 4. Percentage of HIP1 knockdown cells in different phases of the cell cycle. (A) The percentage of cells in the G phase significantly increased, whereas the percentages of cells in the $\mathrm{S}$ and $\mathrm{G}_{2}$ phases significantly decreased in the shRNA-HIP1 group compared with shRNA-control group. (B) Statistical analysis of the percentage of cells in the shRNA-control and shRNA-HIP1 groups. ${ }^{~} \mathrm{P}<0.05$. HIP1, huntingtin interacting protein 1; sh, short hairpin.

wound healing assay demonstrated that shRNA-control cells migrated at a faster rate compared with the shRNA-HIP1 cells (Fig. 3B). Similarly, the results of the Transwell assay demonstrated that shRNA-control cells migrated at a faster rate compared with the shRNA-HIP1 cells (Fig. 3C). The results of the invasion assay demonstrated that the invasive ability of shRNA-HIP1 cells significantly decreased compared with the shRNA-control cells (Fig. 3D).

HIP1 knockdown arrests EC109 cells in the $G_{1}$ phase of the cell cycle. Flow cytometric analysis demonstrated that the percentage of the shRNA-HIP1 group cells in the $G_{1}$ phase was significantly higher than the shRNA-control group (58.70 $\pm 0.05 \%$ vs. 57.82 $\pm 0.15 \%$; $\mathrm{P}<0.05$; Fig. $4 \mathrm{~A}$ and $\mathrm{B}$ ). Conversely, the percentages of the shRNA-HIP1 group cells in the $\mathrm{S}$ phase $(38.44 \pm 0.05 \%$ vs. $37.76 \pm 0.04 \%$; $\mathrm{P}>0.05)$ and $\mathrm{G}_{2}$ phase $(2.85 \pm 0.10 \%$ vs. $4.42 \pm 0.19 \%$; $\mathrm{P}<0.05)$ were significantly lower than the shRNA-control group (Fig. 4A and B). Taken together, these results suggest that inhibiting HIP1 exerts an inhibitory effect on ESCC proliferation by inducing cells to enter the $G_{1}$ phase from the $S$ phase.
Overexpression of HIPl by lentivirus-delivered RNA interfering. The results of the present study demonstrated that HIP1 mRNA and protein expression levels were lower in Kyse30 cells compared with all other ESCC cell lines. Thus, to further investigate the underlying molecular mechanism of HIP1 in ESCC, Kyse30 cells were infected with a lentiviral vector to overexpress HIP1 expression. The infection efficiency of GFP in Kyse 30 cells infected with OE-HIP1 was $>80 \%$ after 3 days of infection, at a MOI of 20 (Fig. 5A). After 3 days, RT-qPCR and western blot analyses were performed to determine the overexpression efficiency, respectively. The results demonstrated that HIP1 mRNA and protein expressions levels were significantly promoted in cells transfected with OE-HIP1 compared with the $\mathrm{OE}$-control and control groups $(\mathrm{P}<0.05$; Fig. 5B and $\mathrm{C})$. The successful establishment of HIP1 gene overexpression provided a useful tool for further investigating the function of HIP1 in ESCC cell lines.

Overexpression of HIPI promotes ESCC cell proliferation, migration and invasion. To determine the effect of HIP1 
A

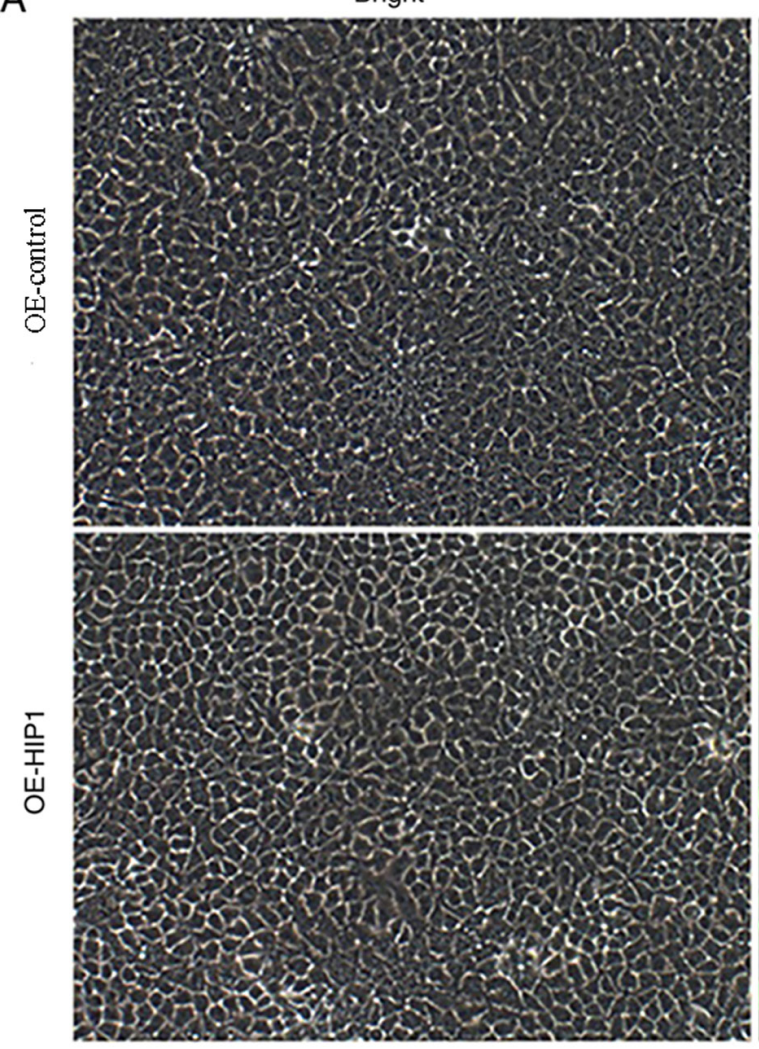

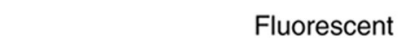

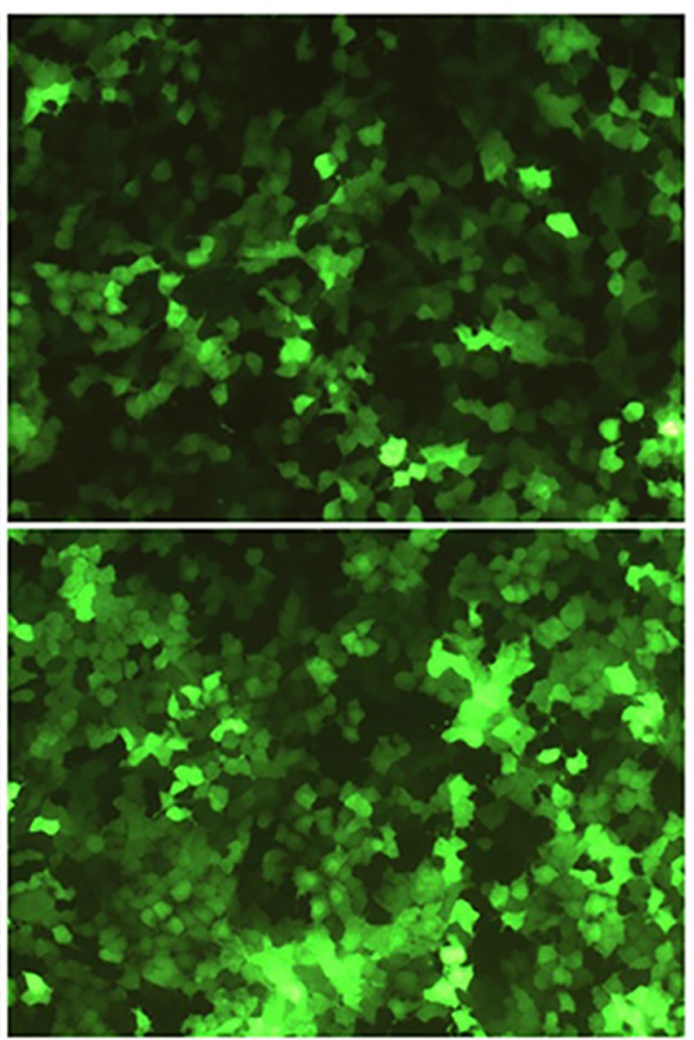

B

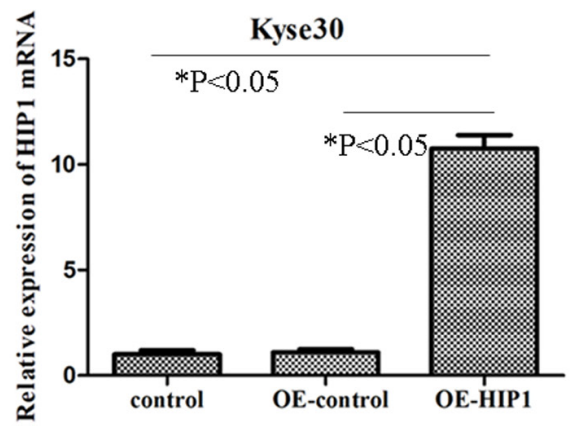

C control OE-control OE-HIP1

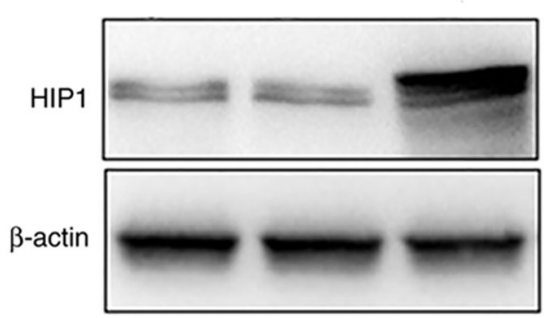

Figure 5. HIP1 expression is significantly overexpressed in Kyse30 cells transfected with OE-HIP1. (A) Micrograph of Kyse30 cells infected with OE-HIP1 for 3 days in bright and fluorescent fields (magnifiation, x100). The results demonstrated that $>80 \%$ of Kyse30 cells infected with OE-HIP1 expressed green fluorescent protein. (B) Reverse transcription-quantitative PCR analysis demonstrated that HIP1 mRNA expression was significantly higher in Kyse30 cells transfected with OE-HIP1 compared the OE-control and control cells. (C) Western blot analysis demonstrated that HIP1 protein expression was remarkably higher in Kyse30 cells transfected with OE-HIP1 compared with the OE-control and control cells. "P<0.05. HIP1, huntingtin interacting protein 1; OE, overexpression.

overexpression on the biological behaviors of ESCC cells, overexpressed HIP1 cells were transfected into Kyse 30 cells. The results of the MTT assay demonstrated that OE-HIP1 cells significantly promoted proliferation compared with the OE-control group ( $\mathrm{P}<0.01$; Fig. 6A). The results of the wound healing assay demonstrated that OE-HIP1 cells migrated at a faster rate compared with the OE-control group $(\mathrm{P}<0.05$; Fig. 6B). Similarly, the results of the Transwell assay demonstrated that OE-HIP1 cells migrated at a faster rate compared with the OE-control group $(\mathrm{P}<0.01$; Fig. $6 \mathrm{C})$. The results of the invasion assay demonstrated that OE-HIP1 cells significantly promoted the invasive ability of Kyse 30 cells $(\mathrm{P}<0.01$; Fig. 6D). Collectively, these results suggest that overexpression of HIP1 in Kyse30 cells may promote ESCC migration and invasion.

Overexpression of HIPI induces Kyse30 cells to enter the $S$ and $G_{2}$ phases from the $G_{1}$ phase. Flow cytometric analysis demonstrated that overexpression of HIP1 decreased the proportion of Kyse 30 cells in the $\mathrm{G}_{1}$ phase $(58.55 \pm 0.48 \%$ vs. $67.31 \pm 0.29 \% ; \mathrm{P}<0.05)$, with concomitant increase in the S phase $(21.97 \pm 0.18 \%$ vs. $17.66 \pm 0.20 \% ; \mathrm{P}<0.05)$ and $\mathrm{G}_{2}$ phase $(19.48 \pm 0.33 \%$ vs. $15.04 \pm 0.09 \% ; \mathrm{P}<0.05)$, compared with the OE-control cells (Fig. 7A and B). Taken together, these results suggest that overexpression of HIP1 may induce Kyse30 cells to enter the $S$ and $G_{2}$ phases from the $G_{1}$ phase of the cell cycle. 
A

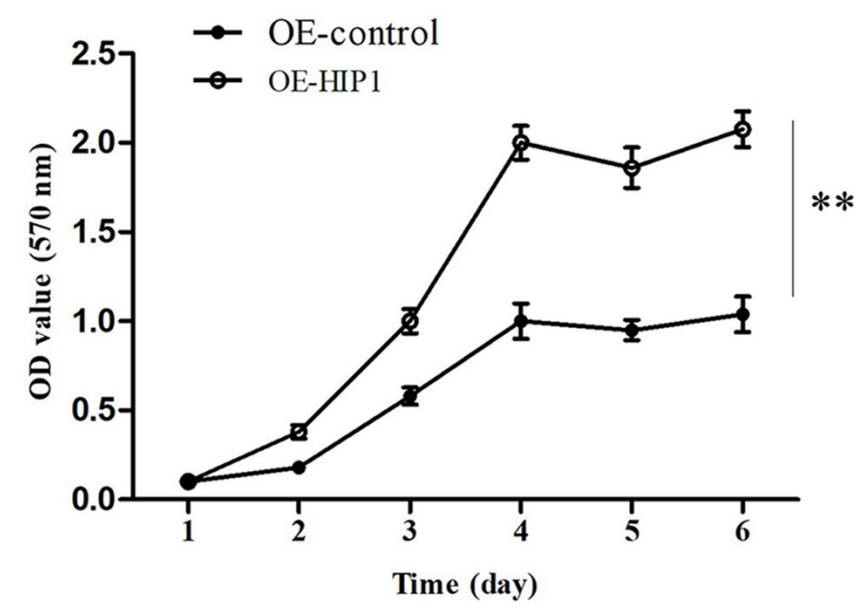

B
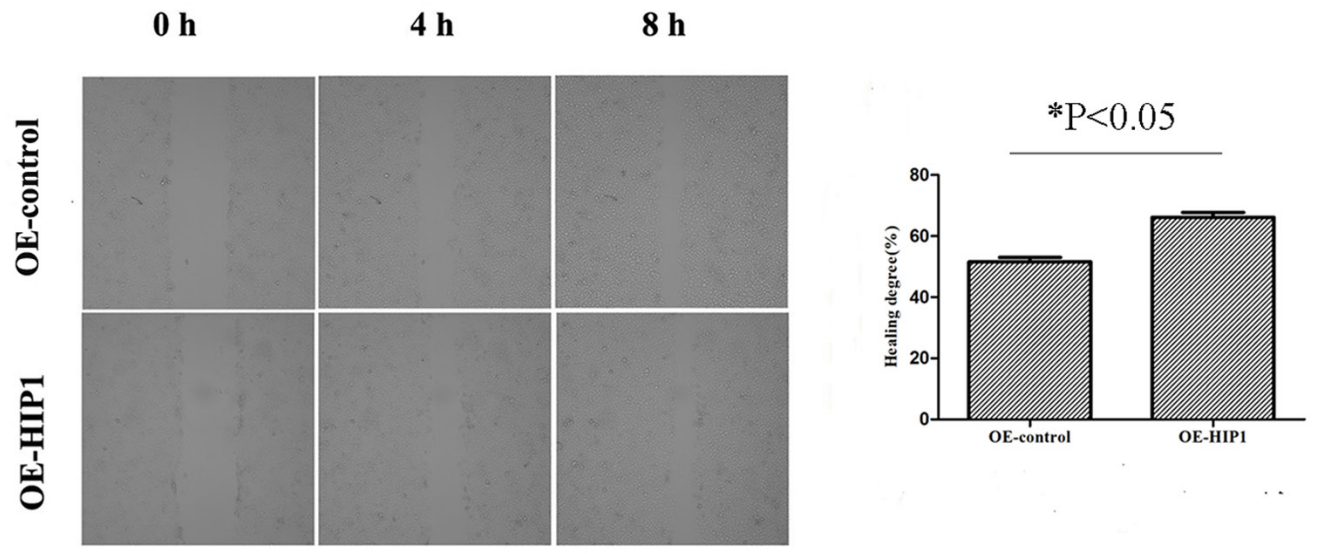

OE-control

OE-HIP1

C
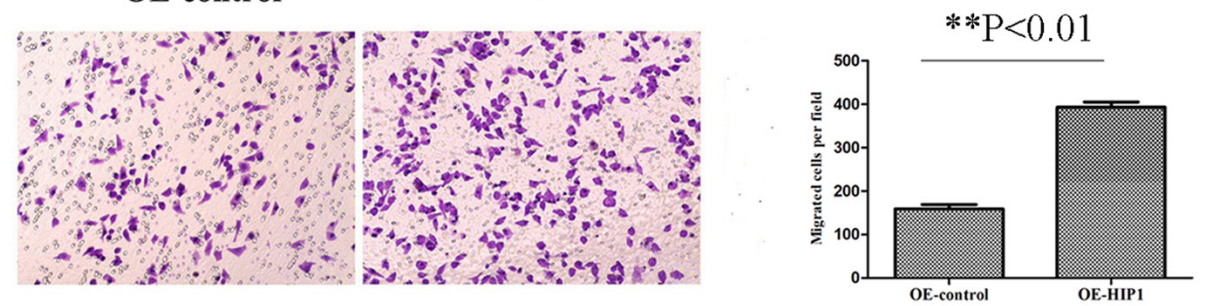

OE-control

OE-HIP1

D
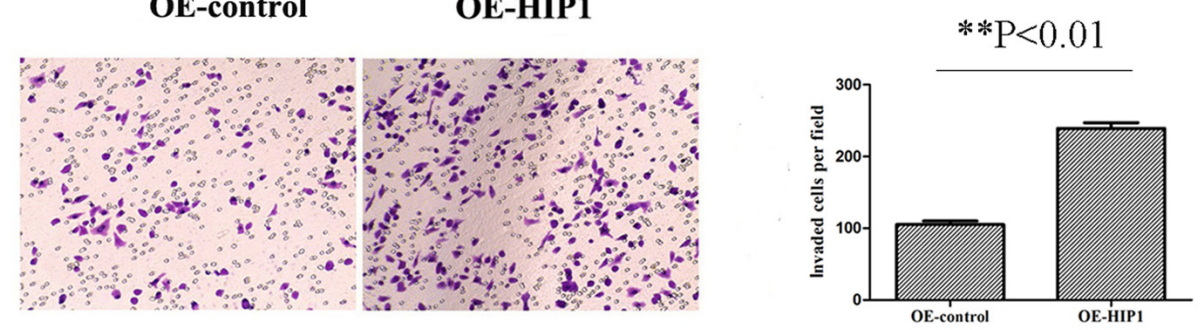

Figure 6. Overexpression of HIP1 significantly promotes esophageal squamous cell carcinoma cell proliferation, migration and invasion. (A) The results of the MTT assay demonstrated that OE-HIP1 promoted the proliferation of Kyse30 cells, in a time-dependent manner, compared with the OE-control group. The (B) wound healing and (C) Transwell migration assays demonstrated that overexpression of HIP1 promoted the migratory ability of Kyse30 cells (magnifications, $\mathrm{x} 100$ and $\mathrm{x} 200$, respectively). (D) The transwell invasion assay demonstrated that overexpression of HIP1 promoted the invasive ability of Kyse30 cells (magnification, $\mathrm{x} 200$ ). ${ }^{*} \mathrm{P}<0.05,{ }^{* *} \mathrm{P}<0.01$. HIP1, huntingtin interacting protein 1; OE, overexpression; OD, optical density.

\section{Discussion}

Efforts of molecular targeted drugs in tumor therapy are encouraging. However, there is a notable lag in the treatment of esophageal cancer, thus it remains critical to identify novel biomarkers for early diagnosis and prognosis prediction. Previous studies have demonstrated the oncogenic function of HIP1, since it association with cancer was reported in 
A
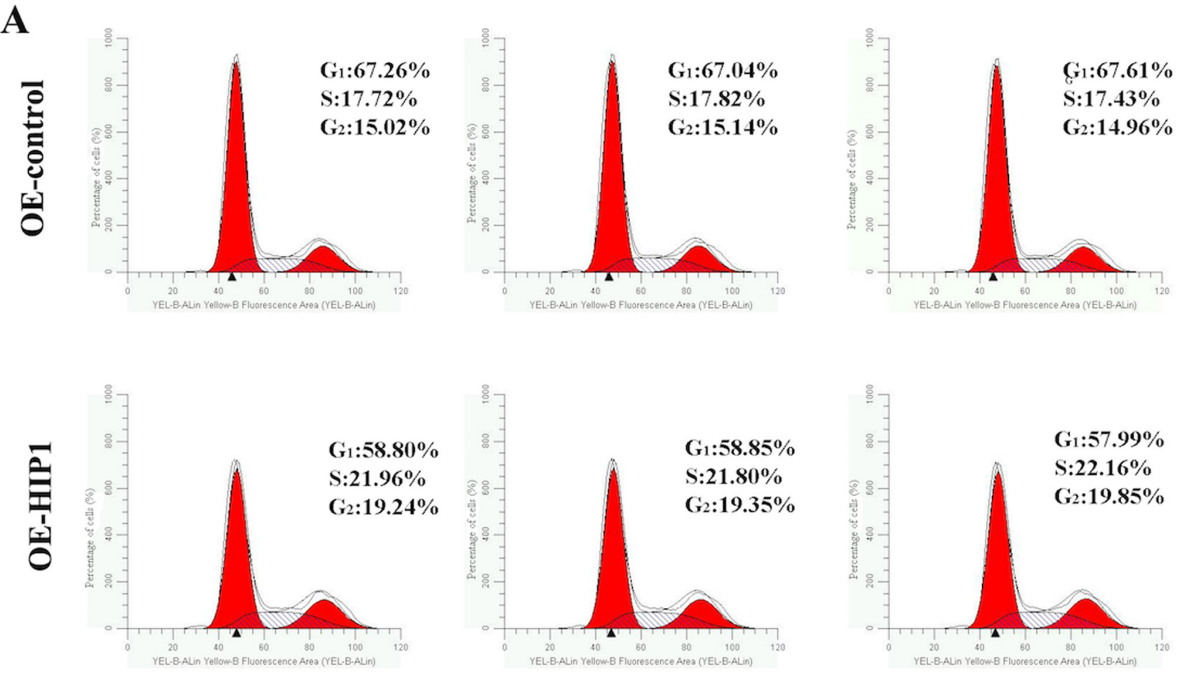

B

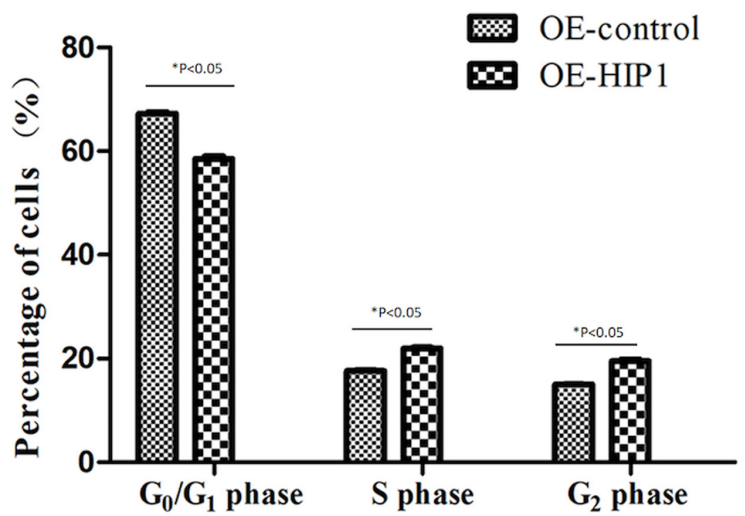

Figure 7. Percentage of HIP1 overexpressed Kyse 30 cells in different phases of the cell cycle. (A) The percentage of cells in the $\mathrm{G}_{1}$ phase significantly decreased, whereas the percentages of cells in the $\mathrm{S}$ and $\mathrm{G}_{2}$ phases significantly increased in the OE-HIP1 group compared with the OE-control group. (B) Statistical analysis of the percentage of cells in the OE-control and OE-HIP1 groups. "P<0.05.

1997-1998 (18,19). These findings suggest that HIP1 may be a novel oncogene in tumors. However, the role and underlying molecular mechanism of HIP1 in ESCC have not yet been reported. Thus, the present study aimed to investigate the role of HIP1 in ESCC tumor progression.

IHC analysis was performed to detect HIP1 expression in 173 patients with ESCC. The results demonstrated that 89.6\% (155/173) of patients with ESCC expressed HIP1. HIP1 mRNA and protein expression levels were also assessed via RT-qPCR and western blot analyses. The results demonstrated that HIP1 mRNA and protein expression levels were significantly higher in ESCC tissues compared with adjacent normal tissues. Wang et al (20) reported that elevated HIP1 expression is present in $67 \%$ of acute myeloid leukemia. By expanding the clinical sample size, the present study confirmed that patients with ESCC have elevated HIP1 mRNA and protein expression levels, suggesting that HIP1 expression is easily detectable in ESCC tissues. Hsu et al (21) demonstrated that low HIP1 expression is associated with clinical stage and inhibits the metastasis in non-small cell lung cancer. The results of the present study demonstrated that HIP1 expression was significantly associated with histological differentiation, TNM stage and lymph node metastasis in patients with ESCC. However, no significant association was observed between HIP1 expression and smoking. Given that alcohol consumption was not included in the clinicopathological data, the association between HIP1 expression and alcohol consumption was not statistically analyzed in the present study. Thus, this will be investigated in prospective studies. In addition, whether there are other genes that cause abnormal HIP1 expression, or whether HIP1 is like the epidermal growth factor receptor gene in lung cancer remains the focus of future research. Taken together, the results of the present study suggest that HIP1 plays an important role in the occurrence and development of ESCC. However, whether HIP1 promotes or inhibits ESCC transfer needs to be confirmed through subsequent experiments.

The effect of different clinicopathological characteristics on the OS time of patients with ESCC was also investigated in the present study. Survival analysis demonstrated that differentiation, TNM stage and lymph node metastasis were all significantly associated with poor prognosis of ESCC. Similarly, Wang et al (20) reported that HIP1 expression is associated with poor prognosis in patients with acute myeloid leukemia. The results of the present study demonstrated that patients with high HIP1 expression had a significantly shorter survival time than patients with low HIP1 expression. Thus, it was hypothesized that HIP1 may be a transforming factor associated with poor prognosis in the development of ESCC. 
Kaplan-Meier survival analysis demonstrated that differentiation, TNM stage, lymph node metastasis and HIP1 expression were all significantly associated with the prognosis of patients with ESCC. Notably, multivariate survival analysis demonstrated that differentiation, TNM stage and HIP1 expression were independent prognostic factors. Given that the TNM stage includes lymph node metastasis, only pathological grade, TNM stage and HIP1 expression were included in the multivariate survival analysis. The results demonstrated that the effect of HIP1 expression was more significant on the prognosis compared with differentiation and TNM stage, which may be closely associated with the importance of HIP1 on the prognosis of patients with ESCC. Collectively, these results suggest that HIP1 may be used as a potential independent biomarker to predict the prognosis of patients with ESCC.

The present study investigated the biological effects of inhibiting and overexpressing HIP1 on ESCC cell mobility in vitro. The results of the MTT, wound healing, and migration and invasion assays demonstrated that overexpressing HIP1 increased the proliferation, migration and invasion of Kyse 30 cells, whereas silencing HIP1 decreased the proliferation, migration and invasion of EC109 cells. Flow cytometric analysis demonstrated that overexpression of HIP1 induced Kyse 30 cells to enter the $S$ and $G_{2}$ phases from the $G_{1}$ phase of the cell cycle, while HIP1 knockdown arrested EC109 cells in the $G_{1}$ phase. The results of the present study demonstrated that HIP1 affected cell cycle as well as cell migration and invasion; however, it is unclear whether these processes involve the same molecular mechanisms. It was speculated that when the esophagus becomes cancerous, HIP1 expression increases, which is accompanied by the proliferation of cancer cells and migration of cells into the $\mathrm{S}$ and $\mathrm{G}_{2}$ phases. However, this speculation requires further investigation. Taken together, these results suggest that high HIP1 expression is closely associated with the development of esophageal cancer.

In conclusion, the results of the present study demonstrated that HIP1 expression was significantly higher in ESCC tissues compared with adjacent normal tissues. In addition, HIP1 expression was significantly associated with histological differentiation, TNM stage and lymph node metastasis. Notably, high HIP1 expression was associated with poor prognosis. Survival analysis demonstrated that HIP1 may be an independent predictor and potential target for patients with ESCC. The results also demonstrated that overexpressing HIP1 promoted ESCC cell proliferation in vitro, while suppressing HIP1 inhibited ESCC cell proliferation by regulating the cell cycle. However, further studies involving animal experiments and clinical trials are required to determine whether HIP1 is a clinical therapeutic target for ESCC.

\section{Acknowledgements}

Not applicable.

\section{Funding}

The present study was supported by the Air Force Medical University Tangdu Hospital Innovation and Development foundation (grant no. 2016JCYJ009).

\section{Availability of data and materials}

The datasets used and analyzed during the present study are available from the corresponding author upon reasonable request.

\section{Authors' contributions}

YaZ, ZZ and TJ designed the present study. YS, JX, XW and YoZ performed the experiments. MW and JZ analyzed the data, and YS, YaZ, ZZ and TJ prepared and revised the manuscript for important intellectual content. All authors have read and approved the final manuscript.

\section{Ethics approval and consent to participate}

The present study was approved by the Regional Ethics Committee for Clinical Research of the Air Force Military Medical University ( $\mathrm{Xi}^{\prime}$ an, China; approval no. TDLL-201712-22). Written informed consent was provided by all patients prior to the study start for use of their medical records and tissue specimens for research purposes.

\section{Patient consent for publication}

Not applicable.

\section{Competing interests}

The authors declare that they have no competing interests.

\section{References}

1. Lee YT, Tan YJ and Oon CE: Molecular targeted therapy: Treating cancer with specificity. Eur J Pharmacol 834: 188-196, 2018.

2. da Cunha Santos G, Shepherd FA and Tsao MS: EGFR mutations and lung cancer. Annu Rev Pathol 6: 49-69, 2011.

3. Mahtani R, Holmes FA, Badve S, Caldera H, Coleman R, Mamounas E, Kalinsky K, Kittaneh M, Lower E, Pegram M, et al: A roundtable discussion of the breast cancer therapy expert group (BCTEG): Clinical developments and practice guidance on human epidermal growth factor receptor 2 (HER2)-positive breast cancer. Clin Breast Cancer 20: e251-e260, 2020.

4. Zhang L, Wang $\mathrm{H}$, Li W, Zhong J, Yu R, Huang X, Wang H, Tan Z, Wang J and Zhang Y: Pazopanib, a novel multi-kinase inhibitor, shows potent antitumor activity in colon cancer through PUMA-mediated apoptosis. Oncotarget 8: 3289-3303, 2017.

5. Kalchman MA, Koide HB, McCutcheon K, Graham RK, Nichol K, Nishiyama K, Kazemi-Esfarjani P, Lynn FC, Wellington C, Metzler M, et al: HIP1, a human homologue of $S$. cerevisiae Sla2p, interacts with membrane-associated huntingtin in the brain. Nat Genet 16: 44-53, 1997.

6. Waelter S, Scherzinger E, Hasenbank R, Nordhoff E, Lurz R, Goehler H, Gauss C, Sathasivam K, Bates GP, Lehrach H and Wanker EE: The huntingtin interacting protein HIP1 is a clathrin and alpha-adaptin-binding protein involved in receptor-mediatendocytosis. Hum Mol Genet 10: 1807-1817, 2001.

7. Metzler M, Legendre-Guillemin V, Gan L, Chopra V, Kwok A, McPherson PS and Hayden MR: HIP1 functions in clathrin-mediated endocy tosis through binding to clathrin and adaptor protein 2. J Biol Chem 276: 39271-39276, 2001.

8. Gottfried I, Ehrlich M and Ashery U: HIP1 exhibits an early recruitment and a late stage function in the maturation of coated pits. Cell Mol Life Sci 66: 2897-2911, 2009.

9. Bradley SV, Smith MR, Hyun TS, Lucas PC, Li L, Antonuk D, Joshi I, Jin F and Ross TS: Aberrant Huntingtin interacting protein 1 in lymphoid malignancies. Cancer Res 67: 8923-8931, 2007. 
10. Marghalani S, Feller JK, Mahalingam M and Mirzabeigi M Huntingtin interacting protein 1 as a histopathologic adjunct in the diagnosis of merkel cell carcinoma. Int J Dermatol 54: 640-647, 2015

11. Rao DS, Hyun TS, Kumar PD, Mizukami IF, Rubin MA, Lucas PC, Sanda MG and Ross TS: Huntingtin-interacting protein 1 is overexpressed in prostate and colon cancer and is critical for cellular survival. J Clin Invest 110: 351-360, 2002.

12. Sun Y, Han Y, Wang X, Wang W, Wang X, Wen M, Xia J, Xing H, Li X and Zhang Z: Correlation of EGFR Del 19 with Fn14/JAK/STAT signaling molecules in non-small cell lung cancer. Oncol Rep 36: 1030-1040, 2016.

13. Zhao J, Zhou Y, Zhang Z, Tian F, Ma N, Liu T, Gu Z and Wang Y: Upregulated fascin1 in non-small cell lung cancer promotes the migration and invasiveness, but not proliferation. Cancer Lett 290: 238-247, 2010.

14. Wang WP, Sun Y, Lu Q, Zhao JB, Wang XJ, Chen Z, Ni YF, Wang JZ, Han Y, Zhang ZP, et al: Gankyrin promotes epithelial-mesenchymal transition and metastasis in NSCLC through forming a closed circle with IL-6/STAT3 and TGF- $3 /$ SMAD3 signaling pathway. Oncotarget 8: 5909-5923, 2017.

15. Liu T, Li WM, Wang WP, Sun Y, Ni YF, Xing H, Xia JH, Wang XJ, Zhang ZP and Li XF: Inhibiting CREPT reduces the proliferation and migration of non-small cell lung cancer cells by down-regulating cell cycle related protein. Am J Transl Res 8: 2097-2113, 2016.

16. Liang CC, Park AY and Guan JL: In vitro scratch assay: A convenient and inexpensive method for analysis of cell migration in vitro. Nat Protoc 2: 329-333, 2007.
17. Donohoe CL and Phillips AW: Cancer of the esophagus and esophagogastric junction: An 8th edition staging primer. J Thorac Dis 9: E282-E284, 2017.

18. Ross TS, Bernard OA, Berger R and Gilliland DG: Fusion of Huntingtin interacting protein 1 to platelet-derived growth factor beta receptor (PDGFbetaR) in chronic myelomonocytic leukemia with $\mathrm{t}(5 ; 7)(\mathrm{q} 33 ; \mathrm{q} 11.2)$. Blood 91: 4419-4426, 1998.

19. Hong M, Kim RN, Song JY, Choi SJ, Oh E, Lira ME, Mao M, Takeuchi K, Han J, Kim J and Choi YL: HIP1-ALK, a novel fusion protein identified in lung adenocarcinoma. J Thorac Oncol 9: 419-422, 2014

20. Wang J, Yu M, Guo Q, Ma Q, Hu C, Ma Z, Yin X, Li X, Wang Y, Pan H, et al: Prognostic significance of huntingtin interacting protein 1 expression on patients with acute myeloid leukemia. Sci Rep 7: 45960, 2017.

21. Hsu CY, Lin CH, Jan YH, Su CY, Yao YC, Cheng HC, Hsu TI, Wang PS, Su WP, Yang CJ, et al: Huntingtin-interacting protein-1 is an early-stage prognostic biomarker of lung adenocarcinoma and suppresses metastasis via Akt-mediated epithelial-mesenchymal transition. Am J Respir Crit Care Med 193: 869-880, 2016.

(i) () This work is licensed under a Creative Commons cc) Attribution-NonCommercial-NoDerivatives 4.0 International (CC BY-NC-ND 4.0) License. 